\title{
Adhesion between the bed and component manufactured in FDM technology using selected types of intermediary materials
}

\author{
Dominika Płaczek ${ }^{1, *}$ \\ ${ }^{1}$ Faculty of Mechanical Engineering, University of Since and Technology, Al. prof. S. Kaliskiego 7, \\ 85-796 Bydgoszcz, Poland
}

\begin{abstract}
FDM technology (Fused Deposition Modeling) is a popular form of additive manufacturing of elements. The development of this technology is related to the need of achieving high accuracy of products and shortening the time of manufacturing. Despite the through of advantages, FDM technology involves several technological problems. One of them is the phenomenon of detaching created element from the bed of the device as a result of processing shrinkage. One of the methods of increasing the adhesion of elements to the bed is the use of glued intermediate materials. Among the available options, there are tapes dedicated to FDM technology, such as adhesive pads. In addition, they are used Kapton and cheaper, cellulose tapes. The article presents the method of testing the adhesion force between element and bed of the device producing in FDM technology and obtained values for the use of various types of intermediary materials. The specimens were made of one of the most commonly used material - PLA. A glass bed was used for the test. The results were compared with values of adhesion force for elements produced on a smooth, uncoated bed. The method and research results allow to compare and select the appropriate method based on empirically determined values.
\end{abstract}

\section{Introduction}

Fused Deposition Modeling technology is a popular method of incremental manufacturing components. This technology consists in applying layer-by-layer of previously plasticized material. The polymeric material introduced into the head, in the form of a filament, is heated to the melting point. The material is extruded through the nozzle onto the bed of the device, after which it congeals in a shape consistent with the digital spatial model [1-3].

Due to its versatility, simplicity of operation and low cost of operation, devices manufacturing in FDM technology have found application in various fields of science and technology [4,5]. Details are often elements of visualization or verification of projects. They are also used to create tooling patterns and molds [6]. The wide possibilities of building prototypes and target devices affect the continuous development of this method

\footnotetext{
*Corresponding author: domiplaczek@gmail.com
} 
$[7,8]$. Progress in the area of rapid prototyping is associated with the desire to obtain high accuracy of products and shortening their production time. Despite the above-mentioned advantages, FDM technology is also associated with several technological problems.

\subsection{Technological problem}

The necessary condition for the correct shape of the product is its permanent sticking to the bed during the manufacturing and its easy peeling off after the process. Fulfilling this condition is one of the main technological problems [9].

The element produced on the bed is held on its surface by adhesion force (rys.1a). The strength of adhesion is usually smaller than the internal cohesion forces of the material of the elements and the bed. As a result of the processing shrinkage, the edge of the produced element breaks off (rys.1b).
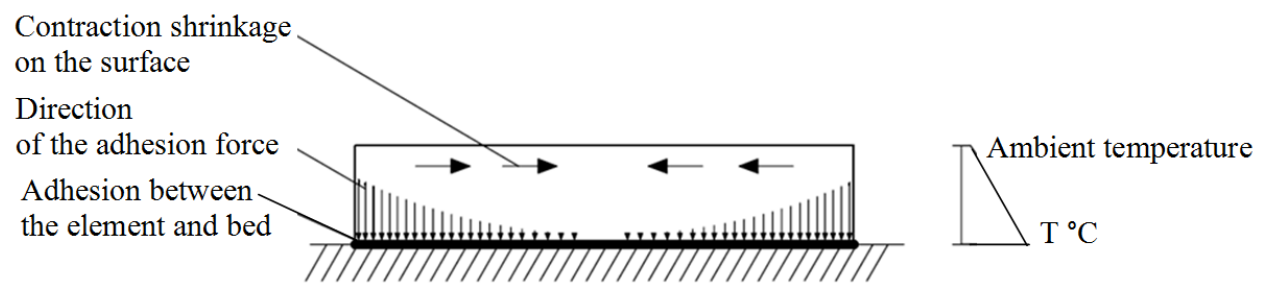

a)

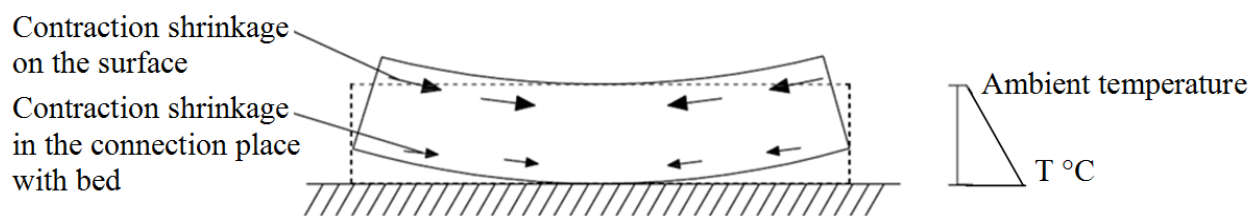

b)

Fig. 1. Diagram illustrating: a) the place of adhesion between the element and the bed of the device, b) peeling off the edges of the element as a result of shrinkage and insufficient adhesion force, where $\mathrm{T}$ is a bed temperature

The appropriate adhesion force between the element and the bed of the $3 \mathrm{D}$ printer prevents them from moving each other [10]. The result of too low adhesion force is the deformation of the manufactured element or its complete separation from the bed of the device.

\subsection{Methods for increasing adhesion force}

In order to increase the adhesion forces between the produced element and the bed 3D printer, various methods are used [9,10-14]. The methods are classified and shown in figure 2 .

For the materials used in FDM technology, there are optimal bed temperatures for the $3 \mathrm{D}$ printer. For some polymer, the lack of a heated bed completely prevents production. It is also essential to choose the material from which the 3D printer bed is made and its structure. Floor panels made of glass, copper, aluminum and perforated platforms are commonly used. Before manufacturing, it is recommended to degrease the bed surface with solvent every time. A thin layer of glue or mixture of plastic with a solvent is also available and easy to apply on a 3D printer bed. Various types of tape are also glued on the surfaces of the bed of the device. Companies offering products and articles applied on the bed of the device. In addition, the Raft, Brim or Skirt methods are used to increase the contact surface 
area of the manufactured part and to extend the manufacturing time (especially of small parts). These methods involve creating additional layers near the element.

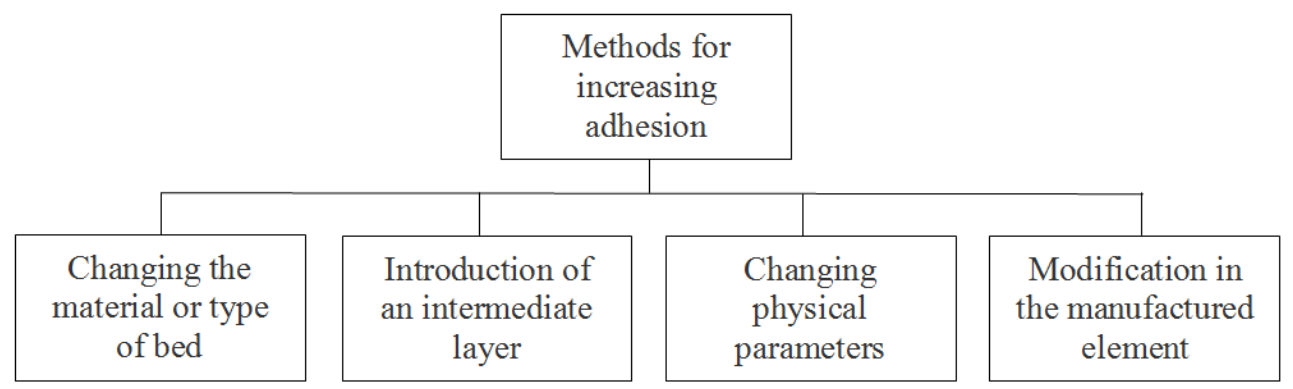

Fig. 2. Classification of methods that increase the adhesion force between the element and the bed of the $3 \mathrm{D}$ printer

\subsection{Types and method of sticking tapes}

Applying tapes on a bed of the rapid prototyping device is one of the methods of increasing the adhesion force between the element and the bed of a 3D printer. The commonly used tapes used by 3D printers include: a blue tape (paper tape), a yellow tape (paper tape), a kapton tape (polyamide tape).

Depending on the width of the tape, they are glued on the whole surface of the bed or partly - in the area of the element's production.

\subsection{Destruction of the connection}

The use of tapes to increase the adhesion force generates additional, possible ways of detaching the produced element from the bed of the rapid prototyping device (fig. 3 ). The introduction of an intermediate layer at the retail-table border affects the possibility of damaging the connection between the tape and the element or tape and the table. The method of destruction depends on the value of the adhesion force between the sample and the tape, the force of the tape and the adhesion and adhesion forces of the adhesive in combination: tape - bed.

\section{Method}

The influence of using different types of tapes to increase the adhesion force between the produced element and the bed of a 3D printer was compared experimentally. The force at which the sample was axially torn off the surface of the tape was measured.

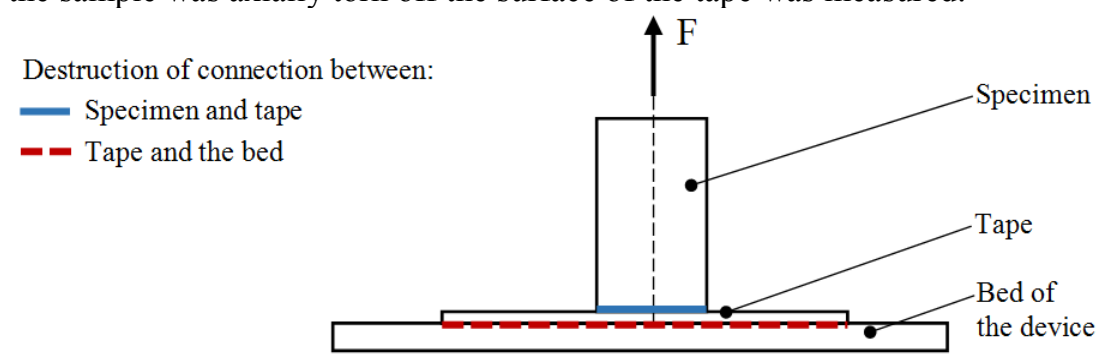

Fig. 3. Places of destruction of the connection 


\subsection{Materials}

The testing was carried out for Polylactide (PLA), which is one of the most commonly used materials in FDM technology. Mechanical properties of polymer are summarized in table 1.

Table 1. Mechanical properties of test material $[15,16]$

\begin{tabular}{|c|c|}
\hline Material & PLA \\
\hline Tensile strength Rm $(\mathrm{MPa})$ & 49 \\
\hline Young's modulus E $(\mathrm{MPa})$ & 3310 \\
\hline Processing temperature $\left({ }^{\circ} \mathrm{C}\right)$ & $200-235$ \\
\hline Melting temperature $\left({ }^{\circ} \mathrm{C}\right)$ & $210 \pm 10$ \\
\hline Glass transition temperature $\left({ }^{\circ} \mathrm{C}\right)$ & 80 \\
\hline Thermal expansion $\left(\mu \mathrm{m} / \mathrm{m}-{ }^{\circ} \mathrm{C}\right)$ & 74 \\
\hline
\end{tabular}

The designed sample was written in a standardized command language: G-code, in which specific production parameters were defined. The parameters are shown in Table 2.

Table 2. Manufacturing parameters

\begin{tabular}{|c|c|}
\hline Material & PLA \\
\hline Extruder temperature $\left({ }^{\circ} \mathrm{C}\right)$ & 220 \\
\hline Extruder nozzle diameter $(\mathrm{mm})$ & 0.5 \\
\hline Filament diameter $(\mathrm{mm})$ & 1.75 \\
\hline Layer height $(\mathrm{mm})$ & 0.3 \\
\hline Quantity top fill pattern solid layers & 2 \\
\hline Quantity bottom fill pattern solid layers & 5 \\
\hline Type of filling & Honey comb \\
\hline Fill density (\%) & 30 \\
\hline
\end{tabular}

A glass having a smooth surface was used as a bed of 3D printer.

5 types of tapes were used for the tests. A description of the types of tapes is summarized in table 3.

\subsection{Test method}

The comparison of values of adhesion forces between the manufactured element and the bed of the 3D printer was carried out on the tedt stand shown in figure 4 . The test was carried out using the DIM200 device producing in FDM technology - and a special testing machine built for this purpose.

Table 3. Types of tape

\begin{tabular}{|c|c|c|c|}
\hline Tape & Material & Glue & Other properties \\
\hline Kapton & Polyamide & Silicone & $\begin{array}{c}\text { Temperature resistance to } 230^{\circ} \mathrm{C} \\
\text { Resistance to chemicals } \\
\text { Extensibility: } 60 \%\end{array}$ \\
\hline Blue & Paper & Acrylic & $\begin{array}{c}\text { Temperature resistance to } 60^{\circ} \mathrm{C} \\
\text { Temperature resistance to } 60^{\circ} \mathrm{C} \\
\text { Extensibility: } 10 \%\end{array}$ \\
\hline Yellow & Paper & $\begin{array}{c}\text { Synthetic } \\
\text { rubber }\end{array}$ & $\begin{array}{c}\text { Temperature resistance to } 60^{\circ} \mathrm{C} \\
\text { Extensibility: } 11 \%\end{array}$ \\
\hline PVC & $\begin{array}{c}\text { Polyvinyl } \\
\text { chloride }\end{array}$ & Acrylic & Water resistant \\
\hline Kinesiology & Cotton & Acrylic & Water resistant \\
\hline
\end{tabular}




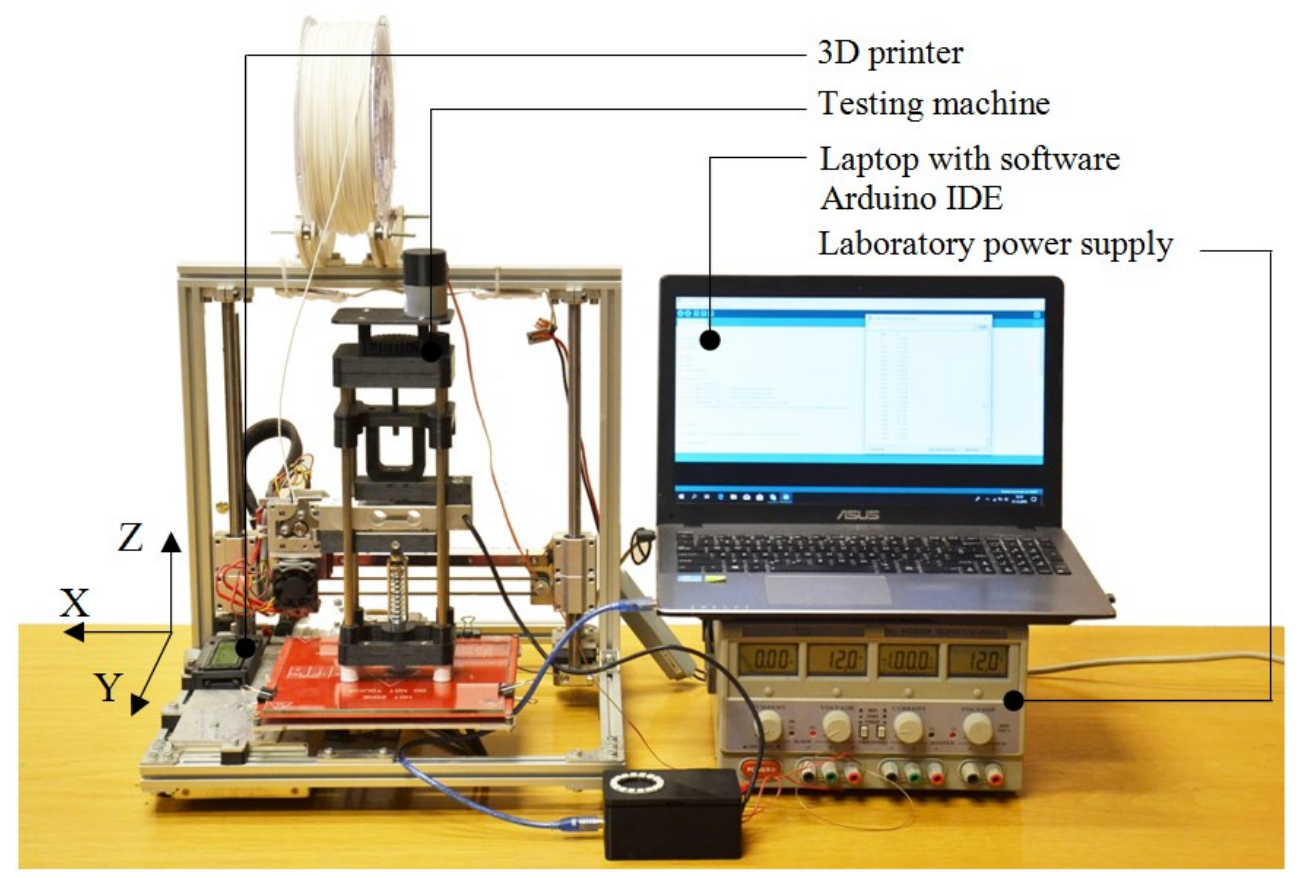

Fig. 4. Test stand for testing adhesion forces between the element and the 3D printer bed

Each time, before the manufacturing process, the table surface was cleaned with a solvent, then a 50x50 mm tape was glued (figure 5a). Specimens with a circular crosssection of $\varnothing 12 \mathrm{~mm}$ were accepted for the tests (figure $5 \mathrm{~b}$ ). Two samples were generated at one time. After finishing the manufacturing process, specimens was left on the bed of 3D printer. The temperature of the bed did not change, it remained equal to the temperature during manufacture. Then, the testing machine was placed directly on the bed of the 3D printer so that the specimen was aligned axially with respect to the axis of the measuring device. After attaching the specimen to the testin machine holder, the test was started. The time and force measured in a given unit of time were recorded in which a specimen or tape was detached from the 3D printer bed. Measurements were made using five types of tapes that adhere to a bed at $70^{\circ} \mathrm{C}$ and an ambient temperature of $20^{\circ} \mathrm{C}$.

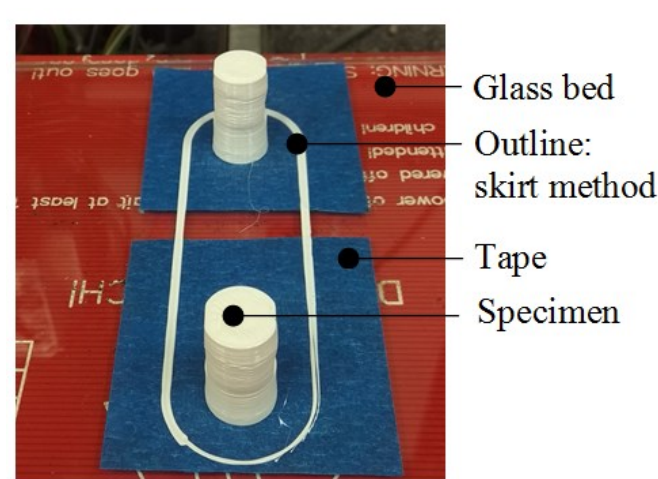

a)

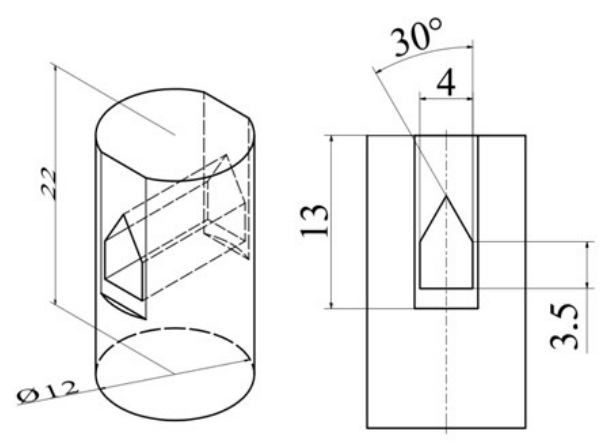

b)

Fig. 5. Scheme: a) placement of tapes and specimens on the bed of a 3D printer, b) of the specimen used for the tests 


\section{Results}

On the basis of the obtained values, it was possible to determine the impact of the use of different types of tapes on the adhesion of elements manufactured from PLA. The result of the test is a graph (figure 6) with averaged values of forces for particular types of tapes and two bed temperatures of a 3D printer. The results are also presented in the form of a table 4 . The results of force measurements were averaged and the standard deviation calculated.

The results were compared with values of adhesion forces obtained using a glass bed with a smooth surface. Eight samples were tested for each case.

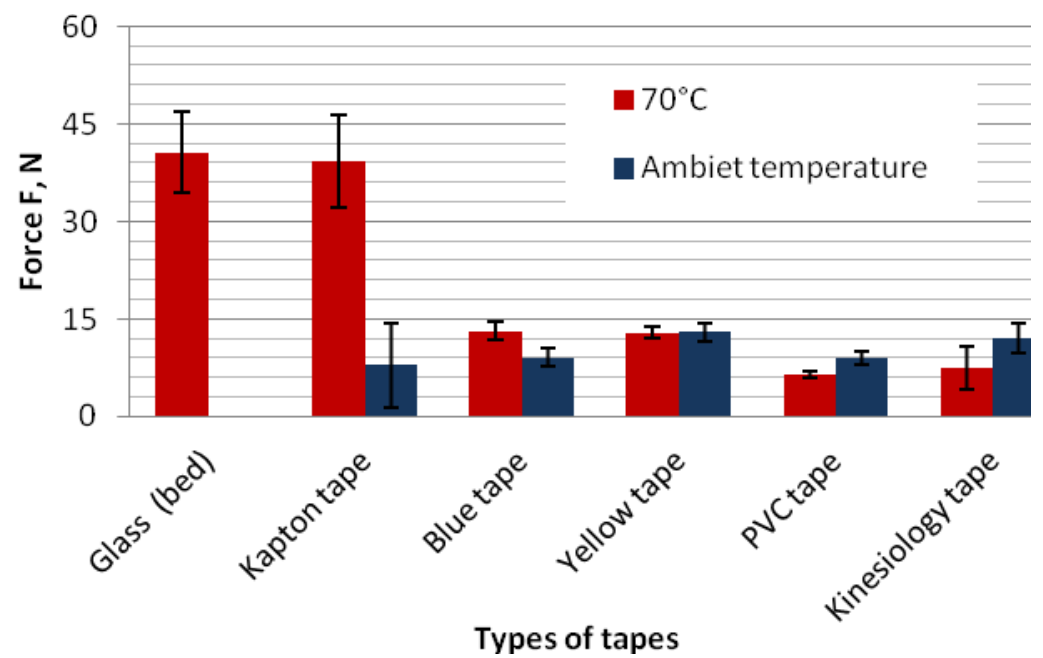

Fig. 6. Results of test on the impact of the use of different types of tapes on the surface of the 3D printer table on the value of the adhesion force of the manufactured elements

Figure 7 shows three different types of joint damage due to axial detachment of specimens. Differences are shown on the basis of the tape: yellow - detachment of the specimen from the tape, kinesiology - tearing the tape off from the $3 \mathrm{D}$ printer bed, PVC in the first stage the tearing off the tape, then detaching the specimen (fig.8).

Table 4. Measurement data

\begin{tabular}{|c|c|c|c|c|c|c|}
\hline & \multicolumn{7}{|c|}{ Peel force F, N } \\
\cline { 2 - 7 } & Glass (bed) & Kapton tape & Blue tape & Yellow tape & PVC tape & $\begin{array}{c}\text { Kinesiology } \\
\text { tape }\end{array}$ \\
\hline $70^{\circ} \mathrm{C}$ & 40.63 & 39.24 & 13.18 & 12.87 & 6.46 & 5.54 \\
\hline $\begin{array}{c}\text { Ambient } \\
\text { temperature }\end{array}$ & 0.00 & 7.85 & 9.08 & 12.96 & 8.94 & 11.10 \\
\hline & 6.34 & 7.06 & 1.49 & 0.92 & 0.49 & 0.34 \\
\hline $70^{\circ} \mathrm{C}$ & 6.58 & 1.46 & 1.43 & 1.08 & 0.25 \\
\hline $\begin{array}{c}\text { Ambient } \\
\text { temperature }\end{array}$ & 0.00 & 6.58 & \multicolumn{7}{|c|}{ Standard deviation, N } \\
\hline
\end{tabular}




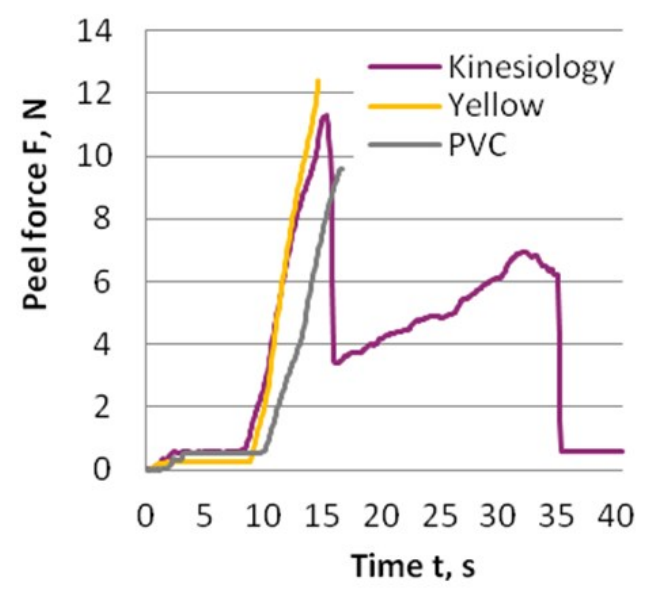

Fig. 7. The connection destruction proces as a result of axial removal of specimen for a bed temperature of $20^{\circ} \mathrm{C}$

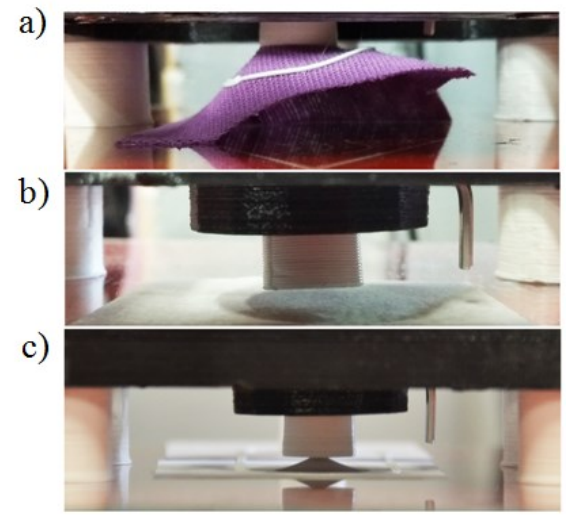

Fig. 8. Methods of detaching specimens using: a) kinesiology tape, b) yellow tape, c) PVC

Methods of detaching specimens depending on the tape used are compared in table 5.

Table 5. Methods of detaching the specimen using different types of tapes

\begin{tabular}{|c|c|c|c|c|c|}
\hline \multirow{2}{*}{ Bed temperature } & \multicolumn{5}{|c|}{ Type of tape } \\
\cline { 2 - 6 } & Kapton tape & Blue tape & $\begin{array}{c}\text { Yellow } \\
\text { tape }\end{array}$ & PVC tape & $\begin{array}{c}\text { Kinesiology } \\
\text { tape }\end{array}$ \\
\hline $70^{\circ} \mathrm{C}$ & & & & & \\
\hline Ambient temperature & & & & & \\
\hline
\end{tabular}

tape from bed, $=$ specimen from tape, first tape from bed and then specimen

In figure 9 is the comparison of the bottom surfaces of the specimens using different types of tapes and fabrication directly on the glass.

a)

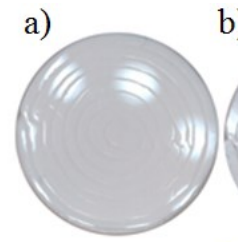

b)
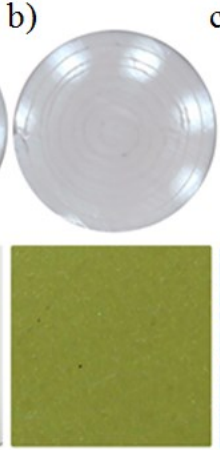

c)
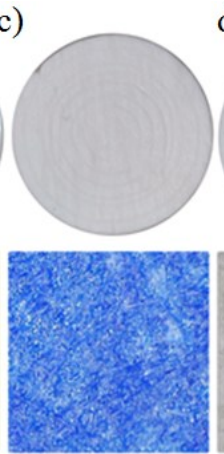

d)
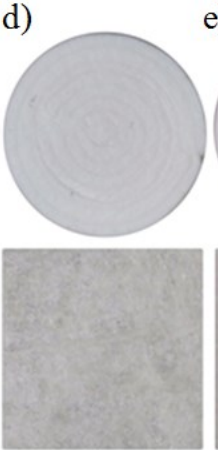

e)
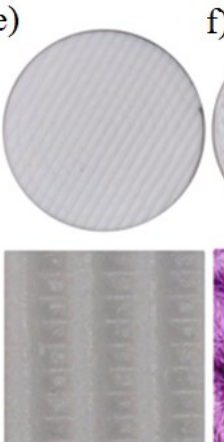

f)
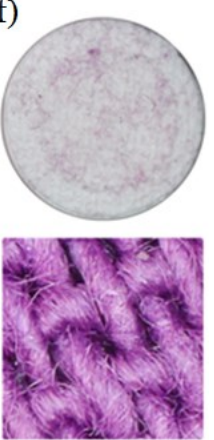

Fig. 9. The surface of the specimen manufactured on: a) glass bed, b) kapton tape, c) blue tape, d) yellow tape, e) PVC tape, f) kinesiology tape

The surfaces of the manufactured elements are the mapping of the glass surface and the tapes used. Specimens made on a glass substrate and kapton tape are characterized by a smooth surface and gloss. The surfaces of the elements made on the blue and yellow tape are similar to each other. They are characterized by low roughness and are devoid of gloss. 
The use of PVC tape has caused a significant increase in roughness. The tape surface has visible, equally spaced recesses that visibly reproduce the bottom surface of the specimen. Kinesiology tape made of cotton reproduces on the specimen an uneven, rough texture with leaving individual, fine threads of material.

\section{Conclusions}

On the basis of experimentally obtained values of adhesion forces, it is possible to compare the effectiveness of using different types of tapes. The use of all types of test tapes enables production with PLA without heating the table. This cannot be achieved when making only on a glass bed. The elements have been torn off the bed at the ambient temperature already in the manufacturing. Heated bed affects the adhesion force between the tape and the specimen as well as the bed and the tape. In the case of kapton and blue tape, the adhesion force is greater for a bed at $70{ }^{\circ} \mathrm{C}$. Not heating the bed for a kapton tape significantly reduced the adhesion force of the element. In two cases the specimen has already been torn off during production. Adhesion force at an equal level for both temperatures was obtained for the yellow tape. In the case of PVC and kinesiology tape, greater forces were obtained for the bed at ambient temperature. In both cases, the connection was broken at the border: tape - bed.

For PLA, the highest adhesion force was obtained for prints produced using a heated bed. In the case of manufacturing on an unheated bed, the highest adhesion force values were obtained for the yellow tape and then kinesiology. Lower values of peel forces were obtained successively to the tape: blue tape, PVC, kapton. The yellow tape is therefore the best and at the same time the cheapest solution increasing the adhesion force between the printed element and the unheated bed.

\section{References}

1. P. Maćkowiak, M. Kotyk, P. Kabat, R. Tomkiewicz, D. Magdziarz, Developments In Mechanical Enginering, 7(4) (2016)

2. M. Allen, W. Chen, C. Wang, $3 D$ Printing Standards and Verification Services, University of California, Berkeley (2015)

3. R. H. Sanatgar, C. Campagne, V. Nierstrasz, Appl Surf Sci., Elsevier, 403 (2017)

4. N. Hopkinson, R. Hague, P. Dickens, Rapid Manufacturing: An Industrial Revolution for the Digital Age, Wiley (2006)

5. S. Dul, L. Fambri, A. Pegoretti, Compos Part A Appl Sci Manuf., 85 (2016)

6. R. E. Williams, V. L. Kormaragiri, P. R. Bishu, J Mater Process Tech., 61(1-2) (1996)

7. C. K. Chua, C. H. Wong, W. Y. Yeong, Standards, Quality Control, and Measurement Sciences in 3D Printing and Additive Manufacturing, Academic Press in and imprint of Elsevier (2017)

8. G. Krolczyk, P. Raos, S. Legutko, Tehnicki Vjesnik-Technical Gazette, 21(1) (2014)

9. M. Spoerk, J. Gonzalez-Gutierrez, J. Sapkota, S. Schuschnigg, C. Holzer, Plast Rubber Compos. 48(1) (2017)

10. D. Płaczek, P. Maćkowiak, P. Świątkowski, Rozwiązanie konstrukcyjne maszyny wytrzymałościowej do odrywania próbek od stotu drukarki $3 D$, Nauka niejedno ma imię Tom V, (2017)

11. M. Kujawa, The influence of first layer parameters on adhesion between the $3 D$ printer's glass bed and $A B S$, Interdyscyplinarność badań naukowych, (2017)

12. C. S. Shafer, D. H. Siddel, A. L. Merriman, A. M. Elliott, Cleated print surface for fused deposition modelling, Solid Freeform Fabrication 2016: Proceedings of the 26th Annual International, (2016)

13. https://rigid.ink/blogs/news/3d-printed-raft-brim-skirt, (14.12.2018) 
14. http://www.powerspec.com/support/3DPrinters/3DPrintingTips.pdf, Fused filament fabrication (FFF) material properties \& considerations, (10.09.2018)

15. http://hbot3d.com/materials/PLA_Hbot3D.pdf, H BOT3D, PLA Technical data sheet, (15.09.2018)

16. A. K. Mohanty, M. Misra, T. L. Drzal, Natural fibers, biopolymers, and biocomposites, Taylor \& Francis Group, (2005)

17. P. Maćkowiak, B. Ligaj, Damage of adhesive single lap joint made of materials with different properties under static loading condition, Enginering Mechanics 2017, (2017)

18. P. Maćkowiak, D. Płaczek, M. Kotyk, Determination of design mechanical properties of adhesives in a tensile and compression test, IOP Conference Series: Materials Science and Engineering, 393 (2018) 